University of Nebraska - Lincoln

DigitalCommons@University of Nebraska - Lincoln

May 1976

\title{
Social and Economic Constraints on Child Life among the !Kung
}

\author{
Patricia Draper \\ University of Nebraska, Lincoln, pdraper1@unl.edu
}

Follow this and additional works at: https://digitalcommons.unl.edu/anthropologyfacpub

Part of the Anthropology Commons

Draper, Patricia, "Social and Economic Constraints on Child Life among the !Kung" (1976). Anthropology Faculty Publications. 13.

https://digitalcommons.unl.edu/anthropologyfacpub/13

This Article is brought to you for free and open access by the Anthropology, Department of at DigitalCommons@University of Nebraska - Lincoln. It has been accepted for inclusion in Anthropology Faculty Publications by an authorized administrator of DigitalCommons@University of Nebraska - Lincoln. 
Published in Kalahari Hunter-Gatherers: Studies of the !Kung San and Their Neighbors, edited by Richard B. Lee and Irven DeVore. Harvard University Press, Cambridge \& London, 1976.

Copyright $\mathbb{0} 1976$ by the President and Fellows of Harvard College. Copyright (c) 1999 by the authors. 
Childhood

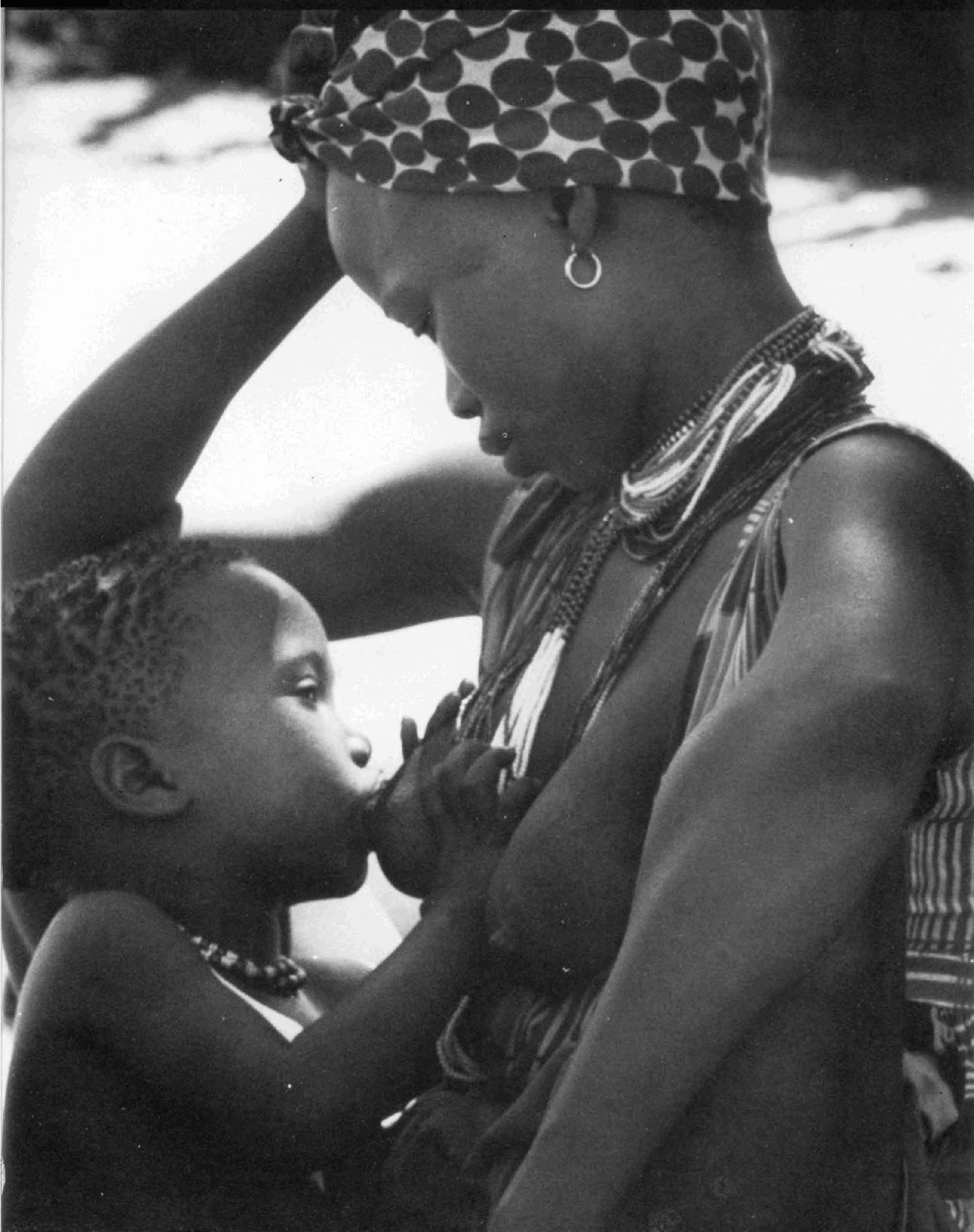


Mother nursing older child 
Social and Economic Constraints

on Child Life among the !Kung

Patricia Draper

Two children sharing water from a hollow tree

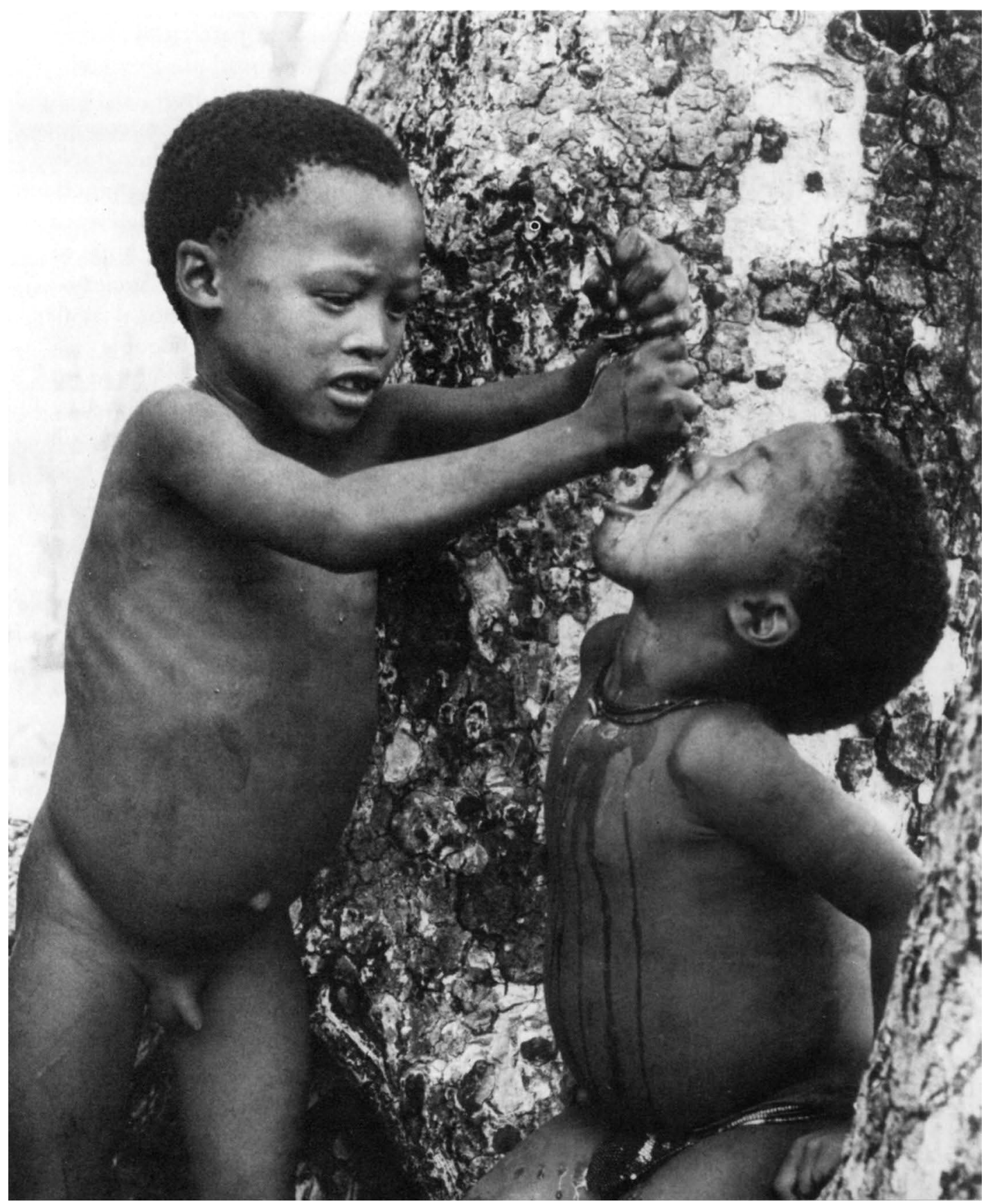




\section{CHILDHOOD}

The usual approach in studies of socialization is to look at the interaction among cultural values, social structure, and child-training practices. The approach used here evolved during my two years in the field living with the !Kung, when it became clear to me that the major constraints on child life derived from the nature of adult work and from the organization of people in space. By the "nature of adult work" I refer to the hunting and gathering subsistence economy, to the rhythm of work routines, and to the accommodation to scarce and unevenly distributed water sources. By "organization of people in space" I refer to the actual settlement pattern of !Kung living groups and to the overlying network of social use to which the living space is put.

In approaching child life through a focus on these more concrete features of social life, I hope not to skimp on the rich ethnographic detail that can be conveyed in writings about child-training practices in other cultures. Instead, by specifying more fully the stage settings and the traffic rhythms of the social actors in camp life, I hope to open to the reader a view of the niche of children in this society.

The / Du/da people were the most isolated and traditionaliof all the !Kung on the border area. During 1969 about 120 people frequented the $/ \mathrm{Du} / \mathrm{da}$ area with usually $60-80$ people (separated into two or more camps) at any one time. Camp size averaged 30-40 people, and the bands were separated by $5.0-50.0 \mathrm{~km}$. The people lived by traditional hunting and gathering techniques and occupied lands not used by Herero and Tswana pastoralists, who lived at /Xai/xai, $66 \mathrm{~km}$ north of the /Du/da well.

Children living in these groups have lives which are markedly different from the lives of western children and different even from the lives of Bantu children in the same geographic area. The most striking contrasts stem from the settlement pattern, the small size of the local group, and the paucity of material goods.

It is difficult to convey a sense of the closeness, intimacy, and isolation of these bush camps. We Westerners combine intensely private domestic life (shared with five or fewer individuals) with daily exposure to hundreds or thousands of total strangers. The !Kung conduct their daily domestic life in the full view of 30-40 relatives and friends and rarely see a stranger. Even when a person visits a camp where some few individuals or families aré unknown, he can always establish a connection with them via mutual relatives and in-laws at other locations.

Some / Du/da camps were sufficiently isolated that casual visiting between bands was not a daily event. During the rainy season camps 
were separated by $16-48 \mathrm{~km}$ though, as the dry season wore on, people retreated to lands near permanent water holes. As an example, in August 1969, 82 people lived in two separate camps near the $\neq$ To//gana well. These people were all well known to each other. The nearest other!Kung at that time were at $/ \mathrm{Xai} / \mathrm{xai}(45 \mathrm{~km}$ to the north) and at $/$ Gəm (15 km to the west).

For someone unaccustomed to the !Kung ways of building huts and laying out a village, it would be possible to walk within six meters of a village and never know it was there. Standing on the outskirts of a !Kung camp for the first time one thinks of birds' nests clinging with frail strength in the branches of bushes. The low, inconspicuous huts are built of branches and grass and so are entirely camoflaged. During most months of the year the people make no effort to clear away grass and bushes from the periphery of the village to mark the disjunction of the open bush with the settled village. People prefer to build their huts backed into the bush and facing into the center of the common village space.

The children living in these camps are limited in their range of movements. It is hardly an exaggeration to say they have almost no place aside from the village and its near periphery where they can go to be by themselves to play games or whatever. There is simply the cleared village space; and in back of each hut stretches the Kalahari bush which from a child's vantage point is vast, undifferentiated, and unsocialized. It was a surprise to me to see what little use children made of the bush hinterland. Older children use the bush beyond eyesight of the village to some extent, but children under about 10 years stayed close to home and most often were inside the village circle in close association with adults.

Inside, the $/ \mathrm{Du} / \mathrm{da}$ camps are small, compact, and densely settled places. The women build the traditional huts at the outer edges of a circular village space. The inner area is usually bare; grass, bushes, small trees are removed so that nothing remains which might have provided shade or privacy. The huts themselves are small (around $1.5 \mathrm{~m}$ tall by $1.8 \mathrm{~m}$ in diameter); and since they are located at the edge of the village space, they do not break up the inner space or create microneighborhoods for certain families. !Kung do not actually live in their houses or use them for privacy. Instead they use their huts primarily for keeping food, skins, and tools dry and as a kind of marker signifying the residence of one nuclear family.

Not only are there no physical barriers to communication within and across the village, there are also no social barriers which restrict the access of people to each other. Women and men, for example, 


\section{CHILDHOOD}

have equal access to all points inside the village, as do children. The only restriction of access is to the inside of another person's hut. Most adults do not go inside the hut of another family, though children may do so. In practice, one rarely finds anyone inside a hut except during a heavy rain or when a person naps there during the heat of an afternoon.

Space within the village is not only small and well-populated, it is also undifferentiated as to function. There is, for example, no children's play area set apart from an "adults only" place. In the village are clusters of interacting people which include people of both sexes and of different ages. In an average village a person can hear the murmur of any conversation anywhere in the village. He might not understand the content of a conversation, but he would hear the voices. In this context everyone is visible at a glance; people are continuously aware of each other's presence, doings, and emotional states. Family huts are often so close together that the people sitting at the different hut fires can converse without raising their voices.

The custom of living in small groups gives a unique stamp to a child's life. Perhaps the single most striking feature is the close association children have with a variety of adults in the band. A child spends most of his days living with a variable assortment of 30-40 people who share the intimate village space. The group includes his own nuclear family and other families and individuals who are usually related to him by blood or marriage. At /Du/da the average band size was 34 people with a range of from 16 to 61 people. The average number of children per band was 5 girls and 7 boys ranging in age from infancy to 14 years. (Table 9.1 shows the age and sex composition of the /Du/da camps during 1969.)

As a consequence of such small total numbers, a child spends little time in the company of age-mates. A typical gang of children joined temporarily in some play in the village might include a 5 -year-old boy, an 11-year-old girl, a 14-year-old boy, and a 2-year-old toddler hanging on the fringe of the action.

The limited and heterogeneous assortment of playmates available to a child poses interesting constraints on the kind of games which children can play. Competitiveness in games is almost entirely lacking, and it is interesting to see that in this respect!Kung cultural values against competitiveness and environmental constraint have such a fortunate congruence. To compete in a game or skill one needs one or preferably more children close in age and perhaps sex with whom to compete, but the smallness of group size among! Kung usually ensures that several age-mates are not available. Team sports 
are similarly unrealistic. Not only can the children not fill out a team; but the players are at such different levels of motor skill, motivation, and cognitive development that it is difficult and unrewarding to play a game involving intense competition, rules, and fairly complex strategy. ${ }^{1}$

An example of a game played by the children may illustrate these remarks. The game, called zeni, is played by both girls and boys; each player takes his turn alone. A feather is joined to a weight (a pebble or an uncracked mongongo nut) with a leather thong about $15 \mathrm{~cm}$ long. The player hurls the weighted feather (zeni) into the air by means of a stick. When the zeni descends, the weight falls first. The feather flutters behind, in a downward spiral, acting as a kind of sail or parachute. The object is for the player to reach the zeni before it lands and to send it back into the air by hooking the stick around the leather thong and hurling it.

The game requires skill, both in timing the catch and in rethrowing the zeni so that it can be hooked and thrown still another time. Each player is clearly striving to perfect his own technique but is not interested in doing better than the previous player. I never observed the children counting the number of times one child threw the zeni without missing; it appeared to me that each new player came into the game for the joy of it and for practicing his own skill.

The setting for zeni play and the typically unequally matched players did not promote a competitive spirit. The children who played usually ranged in age from about 6 to 15 years of age. Their

Table 9.1./Du/da Area: Band size, age and sex composition, places and months of observation

\begin{tabular}{|c|c|c|c|c|c|c|c|}
\hline Period & Date & Place & Census & $\begin{array}{l}\text { Adult } \\
\text { males }\end{array}$ & $\begin{array}{l}\text { Adult } \\
\text { females }\end{array}$ & $\begin{array}{l}\text { Young } \\
\text { males }\end{array}$ & $\begin{array}{l}\text { Young } \\
\text { females }\end{array}$ \\
\hline 1 & Jan. '69 & $/ \mathrm{Du} / \mathrm{da}$ & - & - & - & - & - \\
\hline 2 & Feb.-Mar. '69 & $/ \mathrm{Du} / \mathrm{da}$ & 16 & 5 & 6 & 3 & 2 \\
\hline 3 & Mar.-Apr. '69 & $\neq$ Ticha & 36 & 12 & 12 & 7 & 5 \\
\hline 4 & May'69 & $\neq$ Tebi ! guasi & 45 & 13 & 16 & 11 & 5 \\
\hline 5 & May-June '69 & $\neq$ Tebi !guasi & 56 & 17 & 19 & 12 & 8 \\
\hline 6 & July '69 & $\neq \mathrm{To} / /$ gana & 17 & 4 & 6 & 6 & 1 \\
\hline $7 \mathrm{a}$ & Aug. '69 & $\neq \mathrm{To} / /$ gana $(1)$ & 21 & 6 & 7 & 7 & 1 \\
\hline $7 b$ & Aug. '69 & $\neq \mathrm{To} / /$ gana $(2)$ & 61 & 19 & 22 & 9 & 11 \\
\hline $8 a$ & Sept.' 69 & $\neq \mathrm{To} / /$ gana $(1)$ & 24 & 7 & 10 & 3 & 4 \\
\hline $8 b$ & Sept. '69 & $\neq \mathrm{To} / /$ gana $(2)$ & 32 & 10 & 12 & 4 & 6 \\
\hline $9 \mathrm{a}$ & Oct. ' 69 & $\neq \mathrm{To} / /$ gana $(1)$ & 24 & 9 & 8 & 3 & 4 \\
\hline \multirow[t]{2}{*}{$9 b$} & Oct. '69 & $\neq \mathrm{To} / /$ gana $(2)$ & 40 & 14 & 13 & 6 & 7 \\
\hline & & Averages & 33.8 & 10.6 & 11.9 & 6.5 & 4.9 \\
\hline
\end{tabular}




\section{CHILDHOOD}

skills were so unequal that any rivalry would have been pointless.

In their choice of setting for the game the children reveal a lack of interest in manipulating the environment in order to facilitate the goal of the game. Far from setting the game in a cleared area where the player could have an optimum chance of reaching the zeni as it comes down, the game goes on in the middle of the village or on the periphery just behind the huts. When they play inside the village, the children stumble into huts, narrowly avoid stepping into smoldering hearths, and so forth. When they play on the periphery, they are in the open, unimproved bush and have to dodge around holes in the ground, thorn bushes, ant hills, and fallen logs. As one used to the orderly progress of games played according to rules on a green, graded field, I wondered that the children derived as much satisfaction from throwing the zeni as they did.

More often a youngster is not found in the exclusive company of children but is interacting in a cluster of people which includes at least one and often several adults.

Mother with her four children cracking nuts

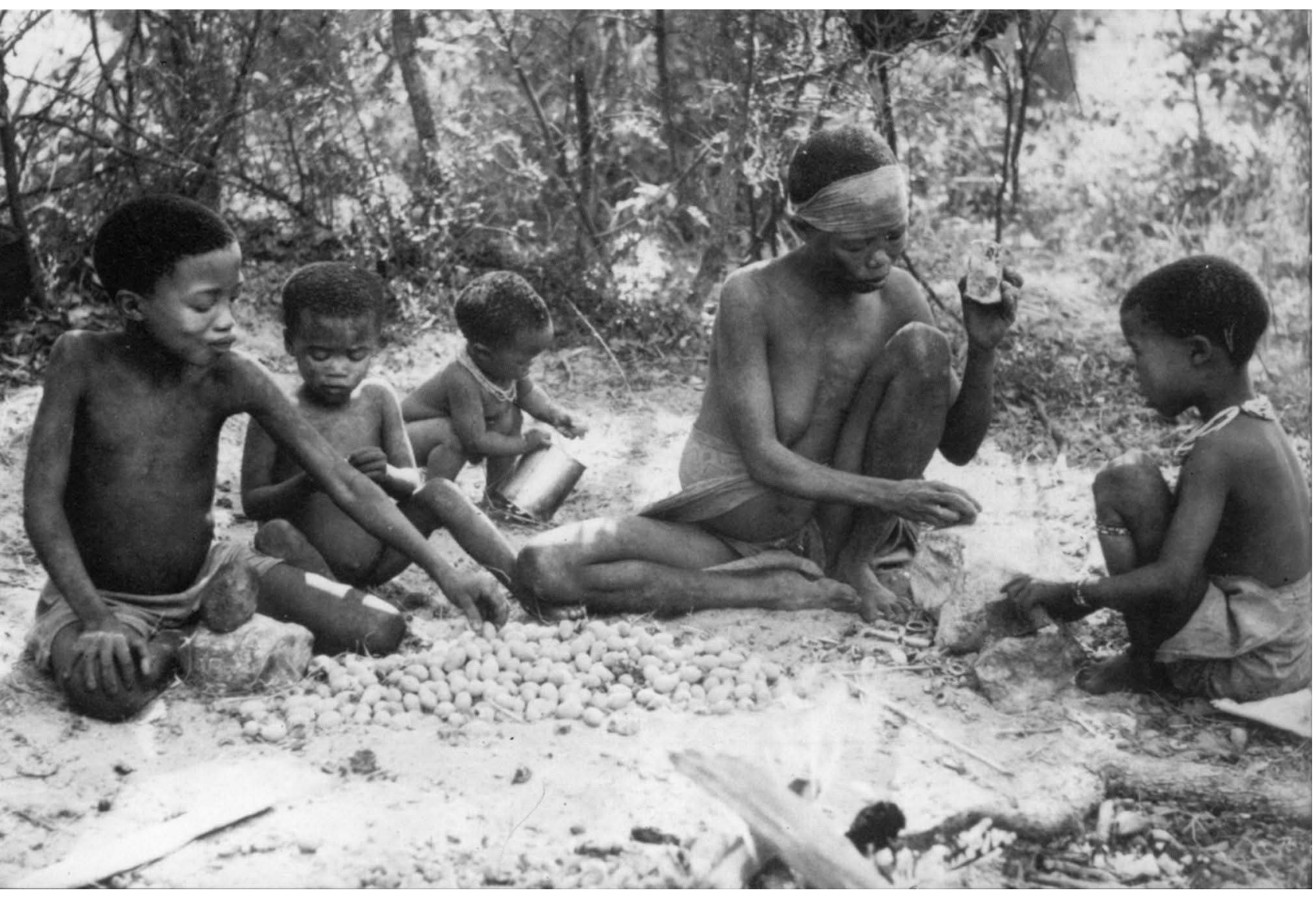


As part of my study of children I collected a series of randomized spot observations at various times during the day on 36 children who lived at $/ \mathrm{Du} / \mathrm{da}$. The spot observation was designed as a quick way of collecting certain data on a child: his location in space; the numbers, ages, sex, and identification numbers of the people who were interacting with him or, who were on the nearby premises. In 173 observations of this type, I recorded no instance in which a child was beyond eye or ear communication with at least one adult. In the same 173 spot observations there were only 5 instances in which a child was "alone" in the sense that he was not in the immediate presence of at least one other person. In these cases the child was either sleeping or walking by himself from one conversational group to another. In about 70 percent of the recorded spot observations children were in face-to-face interactive clusters which included one or more adults.

As described above, the area of village settlement is so small that continuous close physical proximity to adults is unavoidable. Aside from constraints of space, children have great freedom of social access to the adults of the band. During an average day one can expect to find at home half or more of the adults and all the children who are not being carried by their mothers. Adults work 3 to 4 days a week and often less than 8 hours per day. When men and women are not working, they usually stay in the village, sitting in conversational clusters in front of the huts, talking, resting, mending tools and leather garments. Children make virtually no economic contribution to subsistence for reasons which will be discussed more fully later.

Children over 3 years of age are in the village more hours in a 24-hour period than any one else with the exception of very old people who rarely leave camp. If it should happen that a child has neither his mother nor his father within reach, he is nevertheless under the informal but continuous surveillance of the remaining adults and adolescents who are taking the day off from work.

The relationship between children and adults is easygoing and unselfconscious. Adults do not believe that children should keep to themselves: be seen but not heard. The organization of work, leisure, and living space is such that there is no reason for confining children or excluding them from certain activities. Everyone lives on the flat surface of the ground; hence there is no need to protect children from falls or from becoming entrapped behind doors. With the exception of spears and poisoned arrows, adult tools do not constitute a hazard to children. Those weapons are simply kept hanging in trees or wedged on top of a hut, safely out of reach. When the men 


\section{CHILDHOOD}

are making spear and arrow points, they do not attempt to exclude children (or women) from the area. Usually a man sits at his own hearth while he hammers and files the metal.

One afternoon I watched for 2 hours while a father hammered and shaped the metal for several arrow points. During the period his son and his grandson (both under 4 years old) jostled him, sat on his legs, and attempted to pull the arrow heads from under the hammer. When the boys' fingers came close to the point of impact, he merely waited until the small hands were a little farther away before he resumed hammering. Although the man remonstrated with the boys (about once every 3 minutes), he did not become cross or chase the boys off; and they did not heed his warnings to quit interfering. Eventually, perhaps 50 minutes later, the boys moved off a few steps to join some teenagers lying in the shade.

Though the !Kung children are closely supervised, they have considerable leeway despite their continuous physical proximity to adults. Adults are ubiquitous, but they have a nondirective attitude toward the nearby children. In another type of behavior observation I recorded the activity of a child for a 60 -minute period. I varied the time of the observation period over the day and randomized the order for observing each child. During the hour I recorded the child's actions, the actions of others to which he reacted (so far as this could be determined), his commands and commands received, as well as the shifting setting and the shifting set of interactants with whom he was engaged.

Analyzing these data allowed quantification of various aspects of child life. Given the intimate contact between adults and children I wanted to know the extent to which adults (in an overt way) were shaping a child's behavior. I counted the number of times an adult interrupted and changed the behavior of the subject child and as I expected, incidents of this type were infrequent. Girls between the ages of 4 and 14 years received about $1 \frac{1 / 2}{2}$ adult interruptions per hour; boys of the same age range received about 2 adult interruptions per hour.

If adult supervision of children is informal and unobtrusive, it is by no means lax; adults are habitually cognizant of the emotional states and whereabouts of children. Parents are quick to stop aggressive interactions especially when they involve children of unequal ages. They could inform me with great accuracy how to find a child who was beyond eye- and earshot of the village although frequently I was not sensitive enough to the subleties of the directions to find my subject without guidance from another child. To me, ! Kung 
directions were as unhelpful as verbal instructions in how to ride a bicycle would be to a novice cyclist.

The women are especially mindful of the 5- and 6-year-olds who are old enough to wander but too immature to keep oriented in the bush. One hot afternoon at $\neq$ To//gana I was sitting with five women and a few infants. We were all huddled in the shade thrown by a single hut. It was almost too hot to talk; we all sat listlessly, waiting for the sudden lifting of the heat which came everyday at about 5:30 PM. Suddenly one woman jerked herself to a sitting position, neck arched, eyes darting to all directions. "Listen ... listen!" she whispered. "Where are the children?" All the women leapt to their feet, looking about and calling to other people sitting farther off in the village. About that time we hard a child's voice calling in the distance and looking in that direction we saw the missing children: $\mathrm{N} /$ au, a 5-year-old girl, Hwan//ka, a 4-year-old girl, and N!ai, a 9-year-old girl, who were walking through the bush toward the camp. The wave of alarm which had galvanized the women, raised them from torpor, and scattered them twelve or more meters in a few seconds, subsided immediately. Three of the women drifted back to their original positions in the shade of the hut; the other two went to their own hearths and busied themselves at some task. I waited around to see what else might happen. The three girls entered the camp clearing and were apparently oblivious of the concern they had raised for they did not approach any of the women. In the next hour none of the women spoke to the children about their alarm. Probably they felt that there had been no real danger since the 9-year-old girl was present, and since they had apparently not wandered beyond earshot of the camp.

Also quantifiable from the hour observations was the amount of exposure of varying closeness which children had to adults. In developing meaningful parameters for describing the spatial proximity of children to adults I could not rely on the more obvious measures such as being in the same room or village with an adult or being separated by some unit of distance. These measures do not have much meaning in the context of the small, open space of a !Kung village. There are no true rooms in a village, as has been described previously. The village itself is a kind of big room which is the setting for its communal life. A measure of being in the same village with one or more adults contributes no information since children were usually in the village; and when they were, there was at least one (usually several) adult present with him. In fact, in the spot observations and hour observations, when the subject child was in the vil- 


\section{CHILDHOOD}

lage, there were no instances in which he was not near at least one adult.

In the course of recording hour observations there were times when the subject child wandered away from the circle of huts and beyond eye and/or ear communication with the adults of the village. A game or an impromptu gathering expedition was usually the occasion for such an excursion. Such intervals away from adult monitoring were quite brief as is attested by Table 9.2 which shows the average number of minutes per hour observation in which a child was beyond eye and/or ear contact with any adult. My interest in the data of Table 9.2 and those following is in the order of magnitude of the behaviors of various types for !Kung children and not in the heterogeneity among the age-sex categories, for which the numbers are too small to make statistical manipulations useful or meaningful. The distribution of subjects by age and sex category by the hour observations appears in Table 9.3.

The number of subjects is small, and the absence of female subjects in two age categories makes any discussion of the effects of sex and/or increasing age of the variable extremely tenuous. Still, in absolute terms the numbers speak for themselves: /Du/da children are well-supervised; they are seldom left to shift for themselves. These figures also give indirect support for my generalizations earlier to the effect that children make little use of the village hinterland. Similarly, adults do not often go into this hinterland except on their way to work.

Table 9.2. Average number of minutes per hour in which the subject child was completely unsupervised (subjects distinguished by age and sex)

\begin{tabular}{llllll} 
& $2-3$ years & $4-6$ years & $7-9$ years & $10-12$ years & $13+$ years \\
\hline Girls & $-^{\mathrm{a}}$ & $0 \mathrm{~min}$. & $3 \mathrm{~min}$. & $-^{\mathrm{a}}$ & $0 \mathrm{~min}$. \\
Boys & $0 \mathrm{~min}$. & $18 \mathrm{~min}$. & $0 \mathrm{~min}$. & $5 \mathrm{~min}$. & $22 \mathrm{~min}$. \\
\hline
\end{tabular}

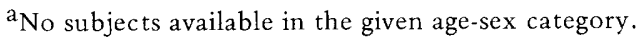

Table 9.3. Ages and numbers of hours observed of /Du/da children ${ }^{\mathrm{a}}$

\begin{tabular}{llllll}
\hline & $2-3$ years & $4-6$ years & $7-9$ years & $10-12$ years & $13+$ years \\
\hline Girls & - & 2 subj. & 3 subj. & - & 1 subj. \\
& & 4 obs. & 4 obs. & & 1 obs. \\
Boys & 1 subj. & 4 subj. & 2 subj. & 3 subj. & 2 subj. \\
& 1 obs. & 5 obs. & 3 obs. & 5 obs. & 3 obs. \\
\hline
\end{tabular}

${ }^{a}$ Total number girls, 6 ; total number boys, 12 : total number of hours observed, 26. 
I settled on two different measures to assess the closeness of child-adult relations. One measure was of spatial proximity. It recorded whether or not there were one or more adults nearby such that the child could see them merely by turning his head. The names and identification numbers of all people in the visual vicinity of the child were recorded. Another measure was of the composition of the child's immediate group of interactants-the people who were in the immediate presence of the child. By "immediate presence of a child" I included only those people who were orienting toward each other and toward the child to the exclusion of other people.

The distinction is meaningful in the context of !Kung culture though it no doubt seems elaborate and unwieldy to people unfamiliar with their customs, particularly as they relate to the maintenance of personal distance. To gain a better understanding of the latter I recommend viewing the excellent ethnographic films by John Marshall which were taken of the !Kung of the nearby Nyae Nyae region. These films convey better than words how physically close they like to be and now much physical contact there is among members of the common living group.

The people live in a rather thick human press; but they screen out (from some levels of consciousness) faces, bodies, and sounds which are not relevant to the immediate activity. For example I occasionally saw five or six individuals squatting around a fire engaging in raucous, bawdy hilarity while another cluster of people not a meter away remained sober-faced and preoccupied with another conversation. We are all familiar with this technique which people employ (or try to) when they are among strangers in a crowded restaurant. What is remarkable to a western observer is that !Kung are able to do this among life-long friends and relatives.

I felt the sociability factor in adult-child dealings was at least important as the proximity factor for the data quantification to be culturally sensitive. Table 9.4 shows the average number of minutes per hour observation in which a child had one or more adults in his immediate presence.

Previously I mentioned that children make virtually no economic

Table 9.4. Average number of minutes per hour in which children have one or more adults in their immediate presence (subjects distinguished by age and sex)

\begin{tabular}{llllll}
\hline & $2-3$ years. & $4-6$ years & $7-9$ years & $10-12$ years & $13+$ years \\
\hline Girls & - & $37 \mathrm{~min}$. & $35 \mathrm{~min}$. & - & $10 \mathrm{~min}$. \\
Boys & $47 \mathrm{~min}$. & $28 \mathrm{~min}$. & $42 \mathrm{~min}$. & $47 \mathrm{~min}$. & $5 \mathrm{~min}$. \\
\hline
\end{tabular}




\section{CHILDHOOD}

contribution to subsistence. In comparison with those in more settled societies, !Kung children are late in being held responsible for subsistence tasks. The girls are around 14-years old before they begin regular food gathering and water and wood collecting. (This is in spite of the fact that they may be married before this age.) Boys are 16 years old or over before they begin serious hunting. The fact that the !Kung can ignore their children for help in subsistence stems chiefly from the nature of adult work and the particular ecological adaptation these people have made which allows a wholesome diet in an apparently inhospitable and intractable environment. The ! Kung are able to feed themselves with relative ease and predictability, and there is little reason to train children for economic self-sufficiency.

Richard Lee has documented for the northern Dobe Area!Kung the amount of work required to support members of the group and the inventory of animal and vegetable species which are used over the years (Lee 1965; 1969a). Although Lee's data refer to another population, the !Kung of the $/ \mathrm{Du} / \mathrm{da}$ area follow weekly work routines essentially similar to those in the north. Some regional dietary variations exist; for example, the $/ \mathrm{Du} / \mathrm{da}$ people ate less mongongo nuts and more game meat than did the Dobe inhabitants. In 1969 some $/ \mathrm{Du} / \mathrm{da}$ groups lived away from standing water for two or more weeks and at these times collected and consumed more water root (!xwa) and prickly melon (ja) than was common in the north where!Kung are more réluctant to dry camp.

At $/ \mathrm{Du} / \mathrm{da}$, as at Dobe, that part of adult work which is concerned with actual food-getting goes on at a distance from camp. Women are the chief gatherers, and they prepare to make gathering trips about every other day. The trips last anywhere from four to ten hours depending on the location of the food and the length of time the group has been collecting from the same base camp. Men also gather, but not routinely. They collect mongongo nuts; and when the group is dry camped (as at $\neq$ Ticha in April, 1969) or camped about $4.8 \mathrm{~km}$ from the waterhole (as at $\neq$ To//gana in August, September, and October 1969), men and women may spend an hour or two per day collecting water root to supplement the standing water which had to be carried from the well to the village.

If children's work is not actually required, it is also true that children can be a hindrance to the work groups of men and women. I found that children do not often accompany adults on their foodgetting rounds. Though it is true that children could follow their parents on their rounds (girls and boys with the women, older boys with men on long hunts), typically they did not. Children prefer to 
stay in the village, to gossip, to play among themselves, and to hang around with the adults who were not working. The children know that the women may wander far on their foraging expeditions, and that the days are extremely hot eight months of the year. The women cannot carry an older child when he becomes tired, for generally they are already carrying an infant or toddler in addition to the day's harvest of bush food. In the dry season when there were no water pans along the way, women actively discouraged children from following them because they didn't want to carry the additional drinking water which the children require.

There are, of course, times when children accompany gathering groups and, to a lesser extent, the hunting parties of the men. These episodes are surprisingly infrequent-just how infrequent I was slow to appreciate. In the first month or two after contacting the $/ \mathrm{Du} / \mathrm{da}$ people I did not carry out formal observations on children, but concentrated on learning the new names and faces, collecting genealogies, making camp diagrams, and trying to overcome the initial unfamiliarity of the $/ \mathrm{Du} / \mathrm{da}$ dialect. In the early weeks I joined the women on gathering trips, primarily intending to build rapport but also to learn how far the women walked, what foods they collected, and how the children behaved on the trips. I was glad to see that several children came along but was puzzled by what I detected as an "air of outing" among them. They were not helping fill their mothers' karosses with the foodstuffs which could be easily collected, and the 8-and 9-year-olds rarely carried even child-size pouches in which to carry food. Off and on they ate handfulls of berries and plugs of sweet edible resin, both of which they gathered themselves. More of the time they scampered through the bush racing each other for first grab at some delicious item, and they hung around me, scrutinizing my dress, my gait, my every move, sometimes with open stare, sometimes surreptitiously.

As the weeks passed and my presence became less of a novelty, I observed that older children seldom accompanied the gatherers even when I did. Several more passing months convinced me that the usual pattern is for children to stay at the village, that in the early weeks they "went gathering" to keep tabs on the strange woman who had inexplicably moved in with their people.

Analysis of the spot observations gives a good indication of the infrequency with which children accompany adult work groups. From a total of 77 spot observations on /Du/da girls there were 8 out of 76 observations (in one case the associates of the girl were not ascertained) in which the subject was absent, and it could be deter- 


\section{CHILDHOOD}

mined for each of these cases whom the girl was with and what she was doing. In 7 instances the girl was absent and reported to be gathering with the women. All but one of these 7 cases represented a girl 3 years or younger. These girls were so young that they were not weaned from the breast and were still carried by their mothers during a day's work. Needless to say, they were not making any contribution to subsistence.

From a total of 96 spot observations on / Du/da boys, there were 18 out of 93 observations (in 3 cases the associates of the boy were not ascertained) in which the subject was absent. Again, it could be determined whom he was with and what he was doing. In only 7 instances were the boys with the men hunting. Six of the 7 observations represented boys 11 years or older. Bush boys accompany women on gathering trips with the same infrequency: 7 in.93 observations. Most of these boys were youngsters, still being carried by their mothers. In no case did a girl go hunting with the men.

Children do not do tasks in the village though they are in the village or close to it most of the day and in close interaction with adults who might easily parcel out the routine work done by adults. For example, cloth garments are scarce in the bush, and the work associated with preparing leather is common, absorbing a fair portion of the days which adults spend in camp. In the /Du/da camps there was usually at least one antelope hide staked out to the rear of the huts. When a hide is completely dry, a man scrapes it with a steel adze. It is monotonous work; the man hunches uncomfortably over the skin and scrapes carefully to avoid gouging a hole in the hide. Children sometimes stand watching this work; they pick up the curly shavings and eat small amounts. I never observed a man who was working at this job attempt to get help from his own or another child. Nor did the man volunteer information or advice about how the job was done. He simply worked with the children squatting at the edge of the hide watching and nibbling with apparent abosrption, then moving on to some other pastime.

When the scraping is finished, women take over the hides and treat them with a softening agent. In the last stage of preparation women spend hours rubbing the hides with a reddish aromatic powder made from a tree bark. They prefer to work the hides with the help of one or two friends; each woman sits with a portion of the skin in her lap, facing her helpers, chatting and smoking. Again, I never observed children helping in any of these tasks, nor in the sewing and tending necessary to make various leather devices. As with the hide scraping by men, I never saw a woman who was working a hide attempt to get help from a nearby child. 
There is one area of daily routine where children give help; this is water collecting. Usually ten or more people (men and women) walk to the waterhole once each day. An adult hands a child a container which he then carries filled to the village. Children do not go every day to the well; they go when they want to, but they help out if they go.

In the course of recording hour observations on the $/ \mathrm{Du} / \mathrm{da}$ children I noted the child's activities and the duration of various activityepisodes. It was possible to derive from the hour observations an estimate of the average number of minutes in an hour in which a child was doing a task. I defined a task as work carried out by a child either because he was told to do so (in my hearing) or because he understood it to be his regular chore. (The latter I determined by interviewing the child's parent when the observation was finished.) I considered that a task was something useful to adults or to the group as a whole. (Child care was not included in the category of children's tasks, but was scored separately and will be discussed later.)

By this measure, children do amazingly little work. The adolescents, theoretically the most capable of their group of doing useful work, were observed doing the least of any age class. Table 9.5 shows the average number of minutes of work per hour done by $/ \mathrm{Du} / \mathrm{da}$ children. Note that an empty cell indicates there were no subjects available in the population of a certain age-sex category.

The short intervals of child work represented in this chart are chiefly cases in which a child executes an informal command by an adult. Typical examples are: fetching a glowing coal for an adult who wants to light his pipe, fetching some utensil as a mortar and pestle for a woman who wants to pound meat or food. Note that the analysis of the hour observations reveals no clear finding of sex difference in task behavior for the /Du/da children. Boys and girls do equally little work. Surprisingly this applies equally to childtending work by boys and girls.

Since their parents are away from home for three to four days per week, one might expect that !Kung children are assigned responsibility for younger children. In most preindustrial societies, particular-

Table 9.5. Average number of minutes per hour in which / Du/da children were observed doing a task (subjects distinguished by age, sex, and subsistence group)

\begin{tabular}{llllll}
\hline & $2-3$ years & $4-6$ years & $7-9$ years & $10-12$ years & $13+$ years \\
\hline Girls & - & $1 \mathrm{~min}$. & $2 \mathrm{~min}$. & - & $0 \mathrm{~min}$. \\
Boys & $0 \mathrm{~min}$. & $.25 \mathrm{~min}$. & $3 \mathrm{~min}$. & $2 \mathrm{~min}$. & $0 \mathrm{~min}$. \\
\hline
\end{tabular}


ly where there is no schooling, older children are expected to take care of younger children. The institution of child nurse is widespread in sub-Saharan Africa in societies where women have a heavy workload (usually agricultural) and must walk some distance to work. These women leave children at the homestead under the tutelage of an older child, usually female. The child nurses are making a substantial contribution to subsistence because they free adult women from continuous child tending.

In actual fact !Kung children devote almost no time to child care as Table 9.6 shows. The data are derived from analysis of the hour observations. Child care is defined to include the following kinds of behavior: the subject wipes face, feeds, amuses, protects from harm, helps dress, or comforts a younger child. Merely talking to a younger child was not counted unless it was accompanied by one of these described acts. Each episode of holding or carrying a younger child was counted once. Originally I tried to score the hour observations for the number of minutes in which the subject was doing something for a child. This proved unsatisfactory; such acts were so fleeting that I had to estimate their duration in seconds, not minutes. A better strategy seemed to make a tally of the discrete acts of child caring.

Various factors are at work to produce the very low scores on child caring. Children do not act as caretakers, because in almost any setting which includes a child there will be several adults present who themselves monitor young childrer. As 1 have indicated before in describing adult work routines, children who stay in the village rather than follow the women on gathering trips do not have the village to themselves. They are still in the company of other adults who are taking the day off. Those child-caring acts which were recorded in the hour observations occur chiefly when the subject child and other younger children are outside the village and out of easy communication with adults. ${ }^{2}$

Still other factors are related to the low scores of $/ \mathrm{Du} / \mathrm{da}$ children on child caring. These are long birth spacing, late weaning from the breast, and late weaning from the back. Children under 3 who need

Table 9.6. Average number of child-caring acts by a subject child per hour of observation (subjects distinguished by age and sex)

\begin{tabular}{llllll}
\hline & $2-3$ years & $4-6$ years & $7-9$ years & $10-12$ years & $13+$ years \\
\hline Girls & - & 0 & 1 & - & 1 \\
Boys & 0 & 1 & .5 & 1.6 & 3.8 \\
\hline
\end{tabular}


the most caretaking stay close to their mothers. When the mother gathers, she normally carries a child under age 2 and is quite likely to carry a child over that age. (Richard Lee 1972d, makes interesting use of the same facts in calculating the work load for mothers of infants of varying ages.) Should a toddler's mother be away temporarily, the child will stay around some other familiar adult, typically the father or a grandparent. The long birth spacing (average 3.8 years) means that most mothers of 2 - to 3 -year-olds are not occupied with another infant and can still devote much of their attention to the knee child (Howell n.d.).

Most children are nursed for at least 3 years and sometimes longer if the mother does not become pregnant. The nursing promotes close ties between mother and child and makes him less independent of her. When a woman miscarries late in pregnancy or produces a stillborn, and she has an older child who is partly or recently weaned; she will put this child back on the breast to drink a renewed supply of milk for several additional months. Normally, in the absence of such a development one would expect that a nursing 3-year-old derives little nutritional benefit from his mother's milk for by then he is eating regularly a standard adult diet. Still, it was obvious to me observing nursing children of this age that the suckling was pleasurable and important to the child's sense of well-being.

At /Du/da I knew a mother, N!oshe, and her son, Kan//ka, who was then about 4 years old. The child was still nursing, though infrequently. I wondered how much if any milk Kan//ka was getting. When I asked N!oshe if her breasts still had milk, she answered, "No, when he nurses he just swallows his own saliva."

This paper has dealt with two dimensions of child life: the high degree of adult supervision and the almost negligible task assignment. The position of children with respect to these dimensions seems in large part determined by the ecological adjustment of !Kung living groups. The high adult supervision of children derives from the interaction of many factors. For example, the semi-nomadism, foraging, and hunting subsistence require minimal investment in housing and communal facilities since each encampment is abandoned after one to several weeks of occupation. Minimal camp furnishings, together with small group size (in turn adapted to efficient extraction of limited and unevenly distributed resources), result in an unusually close, densely occupied, and visually open settlement pattern. The mobility and small size of the groups and the sparse distribution of the entire population over the bush enable the !Kung to exploit a variety of variable food resources and to avoid overharvesting in one area. 


\section{CHILDHOOD}

Adults have considerable time which is not taken up by primary subsistence work such as killing game and collecting vegetable food. They stay at home several days per week and are in close physical proximity to children. The availability of many adults makes possible a loose rein on children in a primarily harmless environment.

The absence of child work seems related both to the predictability of the food supply and to the low level of technological development and the consequent simple, limited material inventory. Living in a relatively rich environment, a normal couple can feed their children and dependent relatives with ease. The nature of adult work (taking place far from camp and away from standing water) means that children cannot be inducted conveniently into adult work.

A simple material technology is both necessary for a people who carry all their possessions on their backs and sufficient if they live wholly off the bounty of the environment. Yet, the very technological simplicity of adult work and the lack of specialization of work conspires to exclude children from early learning of subsistence skills. !Kung subsistence is deceptively simple. It is so uncomplicated that it is easy to overlook the fact that the food-getter must be a mature adult. In more complex societies with more complex economies, food getting is highly rationalized and broken down into smaller packages of work that can be carried out simultaneously by different persons differing in strength, skill, and maturity. In more sophisticated systems there is not food getting but food production, maintenance chores (weeding of crops, husbanding of animals, mending of the tools needed to render food usable), and storage and protection of food surplus.

!Kung economy looks simple in comparison with other more diversified economies with greater division of labor, but from the point of view of the individual actor, subsistence is quite complex. For example, though it is simple enough to pick up nuts or melons once one is standing where they are found, it requires strength to walk $16 \mathrm{~km}$ or more per day carrying a full day's harvest and perhaps a child. A woman needs to know where various foodstuffs are to be found, in what season they are edible, and how to keep oriented in the bush. !Kung women, like their men, pay close attention to animal tracks as they pass through the bush; and they tell the men about recent game movements when they return home in the evening.

The tracks of dangerous animals, particularly snakes, but also big cats and elephants, are immediately noted; and women will sometimes change their course to avoid an unwelcome encounter. When I began accompanying the gathering trips, I learned quickly to follow 
someone's exact footsteps rather than to walk alongside the women who themselves sometimes walked abreast. This was after several occasions when a woman had showed me a snake lying only a few steps away-a snake which my untrained eye never could have spotted. On each occasion my informant knew the name of the snake, whether or not it was dangerous, and enough of its habits to know whether it would be aroused by our nearness. All such bush skills must take years to consolidate before an individual can subsist effectively in the bush.

Other contributors to this volume have mentioned that one justification for studying the ! Kung is that they are relatively pure hunter-gatherers living in an ancient territory, and they in many ways may be typical of South African hunter-gatherers in Paleolithic times. It is interesting to consider the factors I have described and to speculate how typical they may be of hunter-gatherers in general--how factors of small group size, mobility, simple technology can affect the interaction of children with adults and the nature of their training in childhood. 